\title{
Application of postoperative autotransfusion in total joint arthroplasty reduces allogeneic blood requirements: a meta-analysis of randomized controlled trials
}

Weiping $\mathrm{Ji}^{1}$, Xianfeng Lin², Ruoxia Zhang ${ }^{2}$, Pan Tang ${ }^{2}$, Jian $\mathrm{Mo}^{2}$, Xinyi Teng ${ }^{2}$, Qiuping Fan ${ }^{1}$, Bo Wang ${ }^{1}$, Shunwu Fan ${ }^{2}$, Jianfeng Zhang ${ }^{2}$, Shuai Chen ${ }^{2^{*}}$ and Kangmao Huang ${ }^{2^{*}}$

\begin{abstract}
Background: Total joint arthroplasty is associated with significant blood loss and often requires blood transfusion. However, allogeneic blood transfusion (ABT) may lead to severe problems, such as immunoreaction and infection. Postoperative autotransfusion, an alternative to ABT, is controversial. We conducted a meta-analysis to evaluate the ability of postoperative autotransfusion to reduce the need for ABT following total knee arthroplasty (TKA) and total hip arthroplasty (THA).

Methods: Systematic literature searches for randomized controlled trials were performed using PubMed, Embase, and the Cochrane Library until February 2016. Relative risks (RRs) and weighted mean differences with 95\% confidence intervals (Cls) were calculated using fixed-effect or random-effect models; we also evaluated publication bias and heterogeneity.

Results: Seventeen trials with a total of 2314 patients were included in the meta-analysis. The pooled RRs of ABT rate between autotransfusion and the regular drainage/no drainage groups for TKA and THA were 0.446 (95\% $\mathrm{Cl}=0.287,0.693 ; p<0.001)$ and $0.757(95 \% \mathrm{Cl}=0.599,0.958 ; p=0.020)$, respectively. In the subgroup analysis performed in TKA patients according to control interventions, the pooled RRs were $0.377(95 \% \mathrm{Cl}=0.224,0.634$; $p<0.001$ ) (compared with regular drainage) and $0.804(95 \% \mathrm{Cl}=0.453,1.426, p=0.456)$ (compared with no drainage). In the subgroup analysis performed for THA, the pooled RRs were $0.536(95 \% \mathrm{Cl}=0.379,0.757, p<0.001)$ (compared with regular drainage) and $1.020(95 \% \mathrm{Cl}=0.740,1.405, p=0.904)$ (compared with no drainage).

Conclusions: Compared to regular drainage, autotransfusion reduces the need for ABT following TKA and THA. This reduction is not present when comparing autotransfusion to no drainage. However, the reliability of the metaanalytic results concerning TKA was limited by significant heterogeneity in methods among the included studies.
\end{abstract}

Keywords: Postoperative autotransfusion, Total knee arthroplasty, Total hip arthroplasty

\footnotetext{
*Correspondence: cs30518310@163.com; huangkangmao@zju.edu.cn

${ }^{2}$ Department of Orthopaedic Surgery, Sir Run Run Shaw Hospital, Medical

College of Zhejiang University, Hangzhou, China

Full list of author information is available at the end of the article
} 


\section{Background}

Total knee arthroplasty (TKA) and total hip arthroplasty (THA) are major orthopedic surgeries. Both procedures are associated with significant blood loss, generally from bone osteotomies, severed muscles, periosteal bleeding, and some patient-related factors such as bleeding disorders and comorbidities $[1,2]$. It is estimated that perioperative blood loss is between $1000 \mathrm{~mL}$ and $1500 \mathrm{~mL}$ in TKA and that 18-95\% of patients require donor transfusions [3]. Following primary THA, the rate of allogeneic blood transfusion (ABT) can be as high as $30-40 \%[4,5]$. However, ABT can lead to infection with human immunodeficiency virus and hepatitis $C$ [6], allergic reactions, anaphylaxis, hemolytic reactions, lung injury, or graft-versus-host disease [7]. Not only may these conditions undermine the success of the surgery, but can also result in death. Moreover, allogeneic blood resources are limited and expensive.

To establish stable postoperative hemoglobin $(\mathrm{Hb})$ levels and to reduce the need for ABT, various alternatives to donor transfusion have been proposed. For example, there has been support for preoperative blood donation [8,9], acute normovolemic hemodilution [10], erythropoietin injections [11], autologous transfusion systems [12-18], correction of preoperative anemia [19], and pharmacologic agents such as tranexamic acid [20]. The optimal combination of techniques for particular patients and cost-effectiveness remains a matter of debate.

Recently, the concept of reinfusing blood collected from drains following TKA and THA has gained the interest of orthopedists. Drains are used to prevent hematoma accumulation and decrease the possibility of prolonged wound healing and infection [21]. Recent studies have reported that the transfusion of autologous blood has no effect in the majority of cases, but some studies support the method [22-24]. Furthermore, the usefulness of autotransfusion is uncertain due to methodological difficulties, such as no formal power analysis for study size and significance level, different transfusion triggers, and different autotransfusion devices [23]. In order to clarify the issue, we performed a meta-analysis that evaluated $\mathrm{ABT}$ rate, postoperative $\mathrm{Hb}$, and adverse effects after total joint arthroplasty when using autotransfusion drainage, and the use of regular drainage or no drainage.

\section{Methods}

\section{Database search}

A systematic review was performed in accordance with guidelines [25]. All holdings of PubMed, the Cochrane Library, and Embase were searched for relevant trials published until February 2016 using the following terms: (1) "autotransfusion," "autologous blood transfusion," "blood transfusion," or "autologous transfusion"; (2) "total knee arthroplasty," "total knee replacement," "TKA," "total hip arthroplasty," "total hip replacement," or "THA"; and (3) "postoperative," or "post-operation." Only English studies with full texts were included in the final analysis. We chose the most recent study if several publications reported on the same set of patients. The search strategy is provided in Additional file 1.

\section{Inclusion and exclusion criteria}

Eligible literature was carefully identified and selected according to the flow chart in Fig. 1. Studies were included on the basis of the following criteria: (1) a randomized controlled trial (RCT) was designed; (2) the comparison was between a postoperative autotransfusion system and no drainage/regular drainage (i.e., suction drainage, vacuum drainage, hemovac drainage); (3) the results included key data such as transfusion rate; and (4) patients underwent total joint replacement. The exclusion criteria were as follows: (1) an anticoagulant was added to the autotransfusion system; (2) patients underwent bilateral surgery or revision surgery; and (3) patients underwent TKA without a tourniquet because its use would have affected blood loss [26].

\section{Study selection and data extraction}

Two authors (Weiping Ji and Xianfeng Lin) reviewed all titles and abstracts independently to determine which articles met the inclusion criteria. All variables and

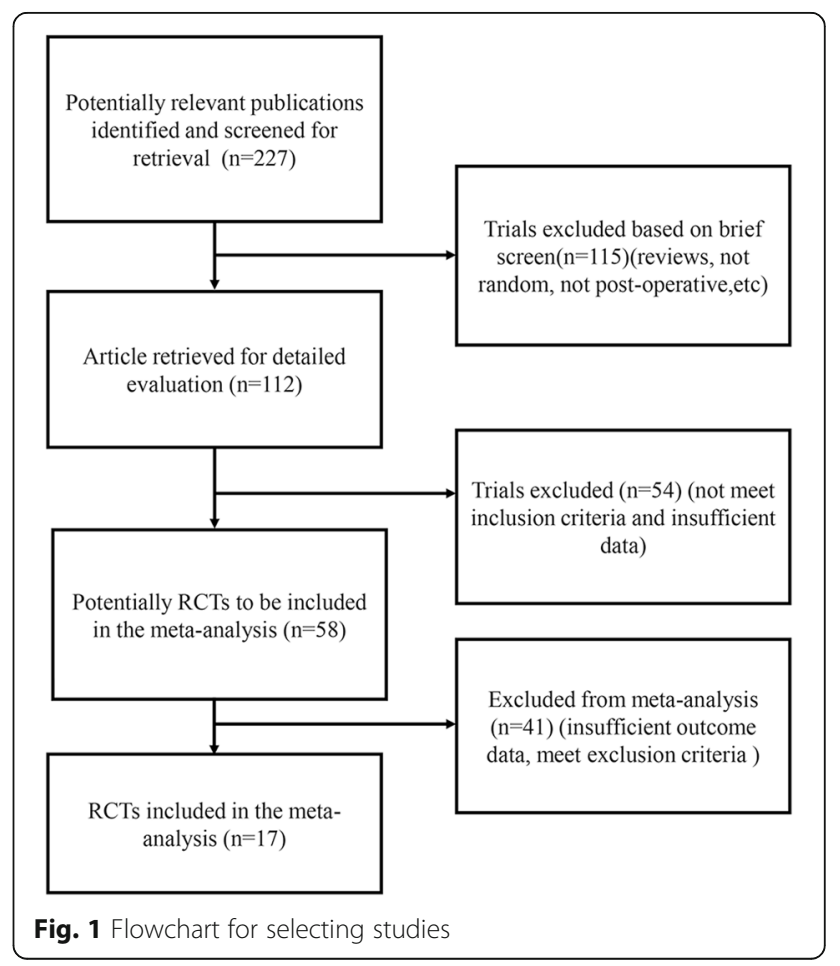


outcomes of interest were extracted independently. The authors solved disagreements by in-person discussion.

The study group referred to the autotransfusion group and the control group encompassed the regular drainage group and no drainage group. We extracted the following characteristics for all studies: year, country of study, type of surgery, population information (age, sample size and gender), autotransfusion systems, and funding sources. The outcomes included the numbers of patients needing allogeneic transfusion, postoperative $\mathrm{Hb}$ levels on day 1 , day 2 , day 3 , and day 5 , and adverse effects. In this meta-analysis, the transfusion rate was the primary outcome and defined as the rate of patients receiving allogeneic transfusion in both the study group and regular drainage/no drainage group postoperatively during hospitalization. The adverse events included complications such as wound infection and febrile reactions recorded in-hospital. Data relating to $\mathrm{Hb}$ levels and adverse effects were extracted to assess recovery after total joint arthroplasty. Blood loss volume, amount of blood transfusion per patient, length of hospital stay, and adverse reactions such as deep vein thrombosis (DVT) and swelling were extracted (data not shown), but the data were insufficient to be included in the meta-analysis.

\section{Validity assessment}

The Cochrane Collaboration's tool was used to assess the bias of all eligible RCTs [27]. The assessment criteria were as follows: (1) the method of randomization was adequate; (2) the treatment allocation was concealed; (3) the groups were similar in the most important prognostic indicators at baseline; (4) the patients were blinded to the intervention; (5) the caregivers were blinded to the intervention; (6) the outcome assessors were blinded to the intervention; (7) co-interventions were controlled; (8) compliance was acceptable in all groups; (9) the dropout rate was described and acceptable; (10) the timing of assessment in all groups was the same; and (11) intention-to-treat analysis was performed. We awarded a score of 1 for each item if it was completely met; scores of $0.5,0$, and N/A were awarded for partly met, not met, and unclear, respectively. The total score of each study was then calculated and the validity scores of $>6$ were considered to represent a low degree of bias.

\section{Statistical analysis}

Statistical analyses were performed with STATA Version 12.0 (StataCorp LP, College Station, TX, USA). Relative risks (RRs) and corresponding 95\% confidence intervals (CIs) were estimated by fixed-effect or random-effect meta-analyses. Weighted mean difference was used to perform meta-analysis for continuous outcomes. The significance of the pooled RRs was evaluated by a Z-test and $p<0.05$. The $\mathrm{I}^{2}$ statistic was used to evaluate heterogeneity. A random-effect model was used when significant heterogeneity was detected among studies $\left(p<0.1, \mathrm{I}^{2}>50 \%\right)$. Otherwise, a fixed-effect model was adopted $\left(\mathrm{I}^{2}<50 \%, p>0.1\right)$. The fixed-effect model was adopted if a small number of studies $(<5)$ were included in the meta-analysis. Considering the source of heterogeneity, the studies were classified by control intervention. To explain some of the clinical heterogeneity observed in the included trials, a subgroup analysis by type of control intervention was performed for the primary outcome. Two sensitivity analyses were performed to assess the stability of pooled effects for TKA and THA. The RRs calculated after excluding a single study were compared with initial effects (before excluding). The results could be considered stable if the RRs did not change significantly (not beyond the initial CI). Egger's test and Begg's test were used to test for publication bias by assessing the association between intervention effects and a measure of study size. Egger's test used actual standardized effect size while Begg's test used ranks of effect sizes and variances. Funnel plots were used to depict asymmetry on visual inspection. A value of $>0.05$ for $\operatorname{Pr}>|z|$ (continuity correct) suggested no publication bias [28]. All $p$-values were two-sided.

\section{Results}

\section{Study characteristics}

Seventeen RCTs [2, 7, 12-18, 22-24, 29-33] were assessed and 2314 patients were included in the metaanalysis (Table 1). Sample sizes ranged from 36 to 231. Three studies included two control groups [13, 18, 33]. Another three studies included two types of surgery: TKA and THA [2, 17, 23]. The criteria for transfusion thresholds were varied and based on authors' experiences, anesthetists' protocols, or hospital policies (data not shown). The data of tranexamic acid use were rarely provided in the included studies. All of the included studies were published in 1992 or later. Validity scores are shown in Table 2 and two studies with validity scores of $<6$ were considered as having a high degree of bias $[16,33]$.

\section{Meta-analysis findings for TKA}

The autotransfusion group had a significantly lower requirement for postoperative ABT $(p<0.001$; RR $=0.446$ [95\% CI $\left.=0.287,0.693] ; I^{2}>50 \%\right)$ than the regular drainage/no drainage group (Fig. 2). Although the autotransfusion group did not show superior reductions in $\mathrm{ABT}$ requirements when compared with the no-drainage group $(p=0.456 ; \mathrm{RR}=0.804$ [95\% $\mathrm{CI}=0.453,1.426]$; $\left.I^{2}<30 \%\right)$, a significant reduction in ABT requirements was noted when compared with the regular drainage group $(p<0.001 ; \mathrm{RR}=0.377$ [95\% $\mathrm{CI}=0.224,0.634]$; 
Table 1 Characteristics of the studies included in the meta-analysis

\begin{tabular}{|c|c|c|c|c|c|c|c|c|c|c|c|}
\hline \multirow[b]{2}{*}{ Study } & \multirow[b]{2}{*}{ Year } & \multirow[b]{2}{*}{ Country } & \multirow[b]{2}{*}{$\begin{array}{l}\text { Type of } \\
\text { surgery }\end{array}$} & \multirow[b]{2}{*}{$\begin{array}{l}\text { Sample } \\
\text { size }\end{array}$} & \multirow[b]{2}{*}{ Age } & \multirow[b]{2}{*}{ Men\% } & \multirow[b]{2}{*}{$\begin{array}{l}\text { transfusion } \\
\text { threshold }(\mathrm{Hb})\end{array}$} & \multicolumn{2}{|l|}{ Study group } & \multicolumn{2}{|c|}{ Control group } \\
\hline & & & & & & & & $\begin{array}{l}\text { Patients } \\
\text { number (n) }\end{array}$ & $\begin{array}{l}\text { Autotransfusion } \\
\text { system }\end{array}$ & $\begin{array}{l}\text { Patients } \\
\text { number (n) }\end{array}$ & Treatment \\
\hline Heddle [12] & 1992 & Canada & TKA & 79 & 70.16 & 35.4 & $<9 \mathrm{~g} / \mathrm{dl}$ & 39 & Solcotrans & 40 & Regular drain \\
\hline Adalberth [13] & 1998 & Sweden & TKA & 73 & 72 & 45.6 & $<9 \mathrm{~g} / \mathrm{dl}$ & 24 & Solcotrans & $\begin{array}{l}25 \\
24\end{array}$ & $\begin{array}{l}\text { Regular drain } \\
\text { No drain }\end{array}$ \\
\hline Thomas [14] & 2001 & UK & TKA & 231 & 69.63 & 42.9 & $<9 \mathrm{~g} / \mathrm{dl}$ & 115 & Cell Saver 5 Haemonetics & 116 & Regular drain \\
\hline Cheng [15] & 2005 & Hong Kong & TKA & 60 & 70.53 & 30 & $<9 \mathrm{~g} / \mathrm{dl}$ & 26 & DONOR & 34 & Regular drain \\
\hline Dramis [29] & 2006 & UK & TKA & 49 & 70.04 & 30.61 & $<9 \mathrm{~g} / \mathrm{dl}$ & 32 & CellTrans & 17 & Regular drain \\
\hline Abuzakuk [30] & 2007 & UK & TKA & 104 & 68.5 & 41.34 & $<9 \mathrm{~g} / \mathrm{dl}$ & 52 & Bellovac & 52 & Regular drain \\
\hline Moonen [17] & 2007 & UK & $\begin{array}{l}\text { TKA } \\
\text { THA }\end{array}$ & $\begin{array}{l}77 \\
83\end{array}$ & 69.25 & 14.38 & ASA classification & $\begin{array}{l}45 \\
35\end{array}$ & $\begin{array}{l}\text { Bellovac, AstraTech AB } \\
\text { Bellovac, AstraTech AB }\end{array}$ & $\begin{array}{l}32 \\
48\end{array}$ & $\begin{array}{l}\text { Regular drain } \\
\text { Regular drain }\end{array}$ \\
\hline Smith [16] & 2007 & UK & THA & 158 & 74.54 & 48.1 & $<8 \mathrm{~g} / \mathrm{dl}$ & 76 & ABTrans & 82 & Regular drain \\
\hline Amin [31] & 2008 & UK & TKA & 178 & 70.35 & 46.07 & $<8 \mathrm{~g} / \mathrm{dl}$ & 92 & Bellovac & 86 & Regular drain \\
\hline Atay [2] & 2010 & Turkey & $\begin{array}{l}\text { THA } \\
\text { TKA }\end{array}$ & $\begin{array}{l}36 \\
41\end{array}$ & $\begin{array}{l}59.33 \\
66.76\end{array}$ & $\begin{array}{l}33.33 \\
21.95\end{array}$ & $<8 \mathrm{~g} / \mathrm{dl}$ & $\begin{array}{l}17 \\
20\end{array}$ & $\begin{array}{l}\text { Transolog } \\
\text { Transolog }\end{array}$ & $\begin{array}{l}19 \\
21\end{array}$ & $\begin{array}{l}\text { Regular drain } \\
\text { Regular drain }\end{array}$ \\
\hline Cheung [18] & 2010 & UK & THA & 153 & 68.12 & 45.1 & $\begin{array}{l}\text { Made by the ward } \\
\text { doctors }\end{array}$ & 53 & Bellovac & $\begin{array}{l}52 \\
48\end{array}$ & $\begin{array}{l}\text { Regular drain } \\
\text { No drain }\end{array}$ \\
\hline Horstmann [32] & 2012 & Netherland & THA & 100 & 68.8 & 27 & ASA classification & 50 & Bellovac & 50 & No drain \\
\hline Kleinert [33] & 2012 & Switzerland & THA & 120 & 65.33 & 49.17 & $<8 \mathrm{~g} / \mathrm{dl}$ & 40 & Bellovac & $\begin{array}{l}40 \\
40\end{array}$ & $\begin{array}{l}\text { Regular drain } \\
\text { No drain }\end{array}$ \\
\hline Sarkanovic [7] & 2013 & Serbia & TKA & 112 & 66.5 & 23.21 & $<8.5 \mathrm{~g} / \mathrm{dl}$ & 55 & Cell Saver & 57 & Regular drain \\
\hline Horstmann [24] & 2014 & Netherland & TKA & 115 & 68.48 & 29.57 & ASA classification & 59 & Bellovac & 56 & No drain \\
\hline Thomassen [23] & 2014 & Netherland & $\begin{array}{l}\text { TKA } \\
\text { THA }\end{array}$ & $\begin{array}{l}165 \\
219\end{array}$ & 68.9 & 25.58 & $<8 \mathrm{~g} / \mathrm{dl}$ & $\begin{array}{l}78 \\
116\end{array}$ & $\begin{array}{l}\text { Bellovac } \\
\text { Bellovac }\end{array}$ & $\begin{array}{l}87 \\
103\end{array}$ & $\begin{array}{l}\text { No drain } \\
\text { No drain }\end{array}$ \\
\hline Teetzmann [22] & 2014 & Norway & THA & 161 & 73 & 37.94 & clinical judgement & 74 & Sangvia & 87 & No drain \\
\hline
\end{tabular}

TKA total knee arthroplasty, THA total hip arthroplasty

$\left.I^{2}>50 \%\right)$. The sensitivity analyses revealed stable results (Additional file 2: Figure S1), namely that the excluded studies did not influence the pooled RRs. The pooled results of post-operation $\mathrm{Hb}$ level (four studies included) suggested that the autotransfusion group had higher post-operative $\mathrm{Hb}$ levels than the regular drainage/no drainage group (Additional file 3: Figure S2). Six studies reported wound infections (three studies included) and febrile reactions (three studies included). We found no significant differences between the autotransfusion group and the regular drainage/no drainage group (Additional file 4: Figure S3). The reliability of these results was limited by the small number of studies included $(<5)$.

\section{Meta-analysis findings for THA}

The autotransfusion group had a significantly reduced need for postoperative ABT $(p=0.020 ; \mathrm{RR}=0.757[95 \%$ $\left.\mathrm{CI}=0.599,0.958] ; I^{2}<30 \%\right)$ than the regular drainage/ no drainage group (Fig. 3). Similar results were found when the autotransfusion group was compared with the regular drainage group and no-drainage groups. Specifically, ABT requirements significantly decreased when the autotransfusion group was compared with the regular drainage group $(p<0.001$; $\mathrm{RR}=0.536[95 \% \mathrm{CI}=0.379$, 0.757]; $\left.I^{2}<30 \%\right)$. However, the autotransfusion group did not demonstrate a significant reduction in ABT requirements compared with the no-drainage group $(p=0.904 ; \mathrm{RR}=1.020[95 \% \mathrm{CI}=0.740,1.405]$; $\left.I^{2}<30 \%\right)$. Sensitivity analyses proved the results to be stable (Additional file 5: Figure S4). The autotransfusion group also had higher $\mathrm{Hb}$ levels (two studies included) compared with the regular drainage/no drainage group (Additional file 6: Figure S5). The pooled results for adverse effects (four studies reporting wound infections and two studies reporting febrile reactions) showed no significant differences between the groups (Additional file 7: Figure S6). The small number of included studies $(<5)$ limited the reliability of these results.

\section{Publication bias}

Egger's and Begg's tests suggested a lack of publication bias with respect to ABT rate (Additional file 8: Table S1). According to this analysis, the included studies were relatively comprehensive and yielded statistically reliable results. The funnel plots did not reveal obvious asymmetry of the included studies (Additional file 9: Figure S7 and Additional file 10: Figure S8). 
Table 2 Risk of bias in included studies

\begin{tabular}{|c|c|c|c|c|c|c|c|c|c|c|c|c|c|}
\hline Study & Year & A & B & C & D & E & $\mathrm{F}$ & G & $\mathrm{H}$ & I & J & K & Total score \\
\hline Heddle [12] & 1992 & 1 & 1 & 1 & 0 & 0 & N/A & 1 & 1 & N/A & 1 & 1 & 7 \\
\hline Adalberth [13] & 1998 & 1 & 1 & 0.5 & 1 & 1 & N/A & 1 & 1 & N/A & 1 & 1 & 8.5 \\
\hline Thomas [14] & 2001 & 1 & 1 & 0 & 0.5 & 1 & N/A & 1 & 1 & N/A & 1 & 1 & 7.5 \\
\hline Cheng [15] & 2005 & 1 & 1 & 0.5 & 1 & 0 & N/A & 0.5 & 1 & N/A & 1 & 1 & 7 \\
\hline Dramis [29] & 2006 & 1 & N/A & 0.5 & N/A & N/A & N/A & 1 & 1 & 0.5 & 1 & 1 & 6 \\
\hline Abuzakuk [30] & 2007 & 1 & 1 & 0.5 & 0.5 & 0.5 & $\mathrm{~N} / \mathrm{A}$ & 1 & $\mathrm{~N} / \mathrm{A}$ & N/A & 1 & 1 & 6.5 \\
\hline Moonen [17] & 2007 & 1 & 1 & 1 & $\mathrm{~N} / \mathrm{A}$ & N/A & N/A & 1 & 1 & 0.5 & 1 & 1 & 7.5 \\
\hline Smith [16] & 2007 & 1 & 1 & 0.5 & N/A & N/A & N/A & 1 & N/A & N/A & 1 & 1 & 5.5 \\
\hline Amin [31] & 2008 & 1 & 1 & 0.5 & 1 & 1 & N/A & 1 & N/A & N/A & 1 & 1 & 7.5 \\
\hline Atay [2] & 2010 & 1 & 1 & 0.5 & N/A & N/A & N/A & 1 & 1 & N/A & 1 & 1 & 6.5 \\
\hline Cheung [18] & 2010 & 1 & 1 & 0.5 & $\mathrm{~N} / \mathrm{A}$ & 0 & N/A & 1 & 1 & N/A & 1 & 1 & 6.5 \\
\hline Horstmann [32] & 2012 & 1 & 1 & 0.5 & 1 & 0.5 & $\mathrm{~N} / \mathrm{A}$ & 1 & N/A & N/A & 1 & 1 & 7 \\
\hline Kleinert [33] & 2012 & 1 & $\mathrm{~N} / \mathrm{A}$ & 0.5 & $\mathrm{~N} / \mathrm{A}$ & N/A & N/A & 1 & N/A & N/A & 1 & 1 & 4.5 \\
\hline Sarkanovic [7] & 2013 & 1 & 1 & 1 & $\mathrm{~N} / \mathrm{A}$ & $\mathrm{N} / \mathrm{A}$ & $\mathrm{N} / \mathrm{A}$ & 1 & $\mathrm{~N} / \mathrm{A}$ & N/A & 1 & 1 & 6 \\
\hline Horstmann [24] & 2014 & 1 & 1 & 0 & 0.5 & 1 & N/A & 1 & 1 & N/A & 1 & 1 & 7.5 \\
\hline Thomassen [22] & 2014 & 1 & 1 & 0.5 & $\mathrm{~N} / \mathrm{A}$ & N/A & 1 & 1 & 1 & N/A & 1 & 1 & 7.5 \\
\hline Teetzmann [23] & 2014 & 1 & N/A & 0.5 & N/A & N/A & N/A & 1 & 1 & 1 & 1 & 1 & 6.5 \\
\hline
\end{tabular}

$R C T$ randomized controlled trial, N/A not clear

Eleven Cochrane Back Review Group criteria: (A) the method of randomization was adequate; (B) the treatment allocation was concealed; (C) the groups were similar in the most important prognostic indicators at the baseline; (D) the patients were blinded to the intervention; (E) the caregivers were blinded to the intervention; $(F)$ the outcome assessors were blinded to the intervention; $(G)$ co-interventions were controlled; $(H)$ compliance was acceptable in all groups; $(\mathrm{I})$ the dropout rate was described and acceptable; $(\mathrm{J})$ the timing of assessment in all groups was the same; and (K) intention-to-treat analysis was performed

\section{Discussion}

We conducted a meta-analysis to determine the effectiveness and safety of postoperative autotransfusion for TKA and THA. The findings revealed that postoperative autotransfusion could significantly reduce the number of patients who require postoperative $\mathrm{ABT}$ for TKA and THA compared with patients who receive regular drainage. However, the effect was not sustained when comparing autotransfusion with no drainage. The autotransfusion group had higher $\mathrm{Hb}$ levels than the regular

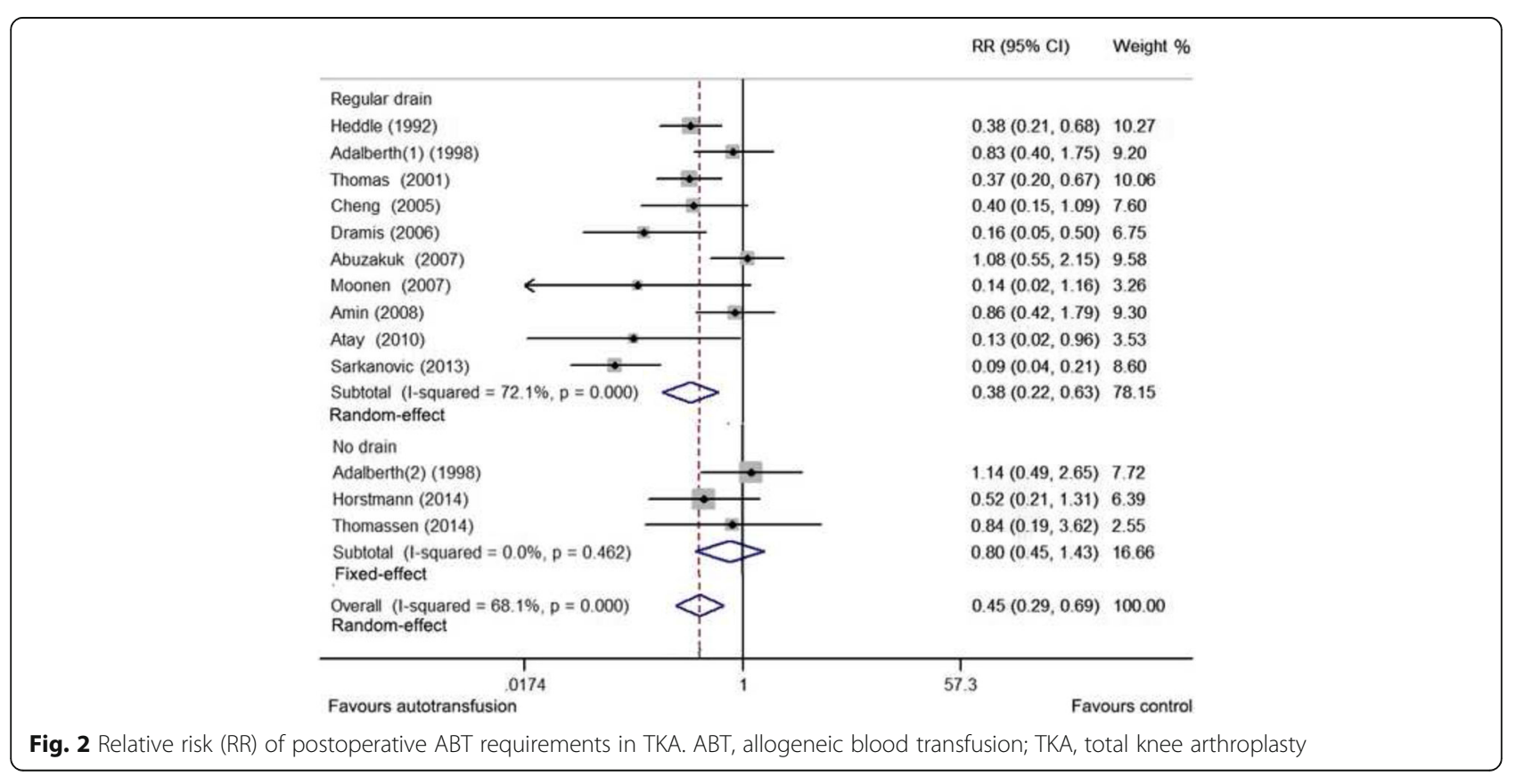




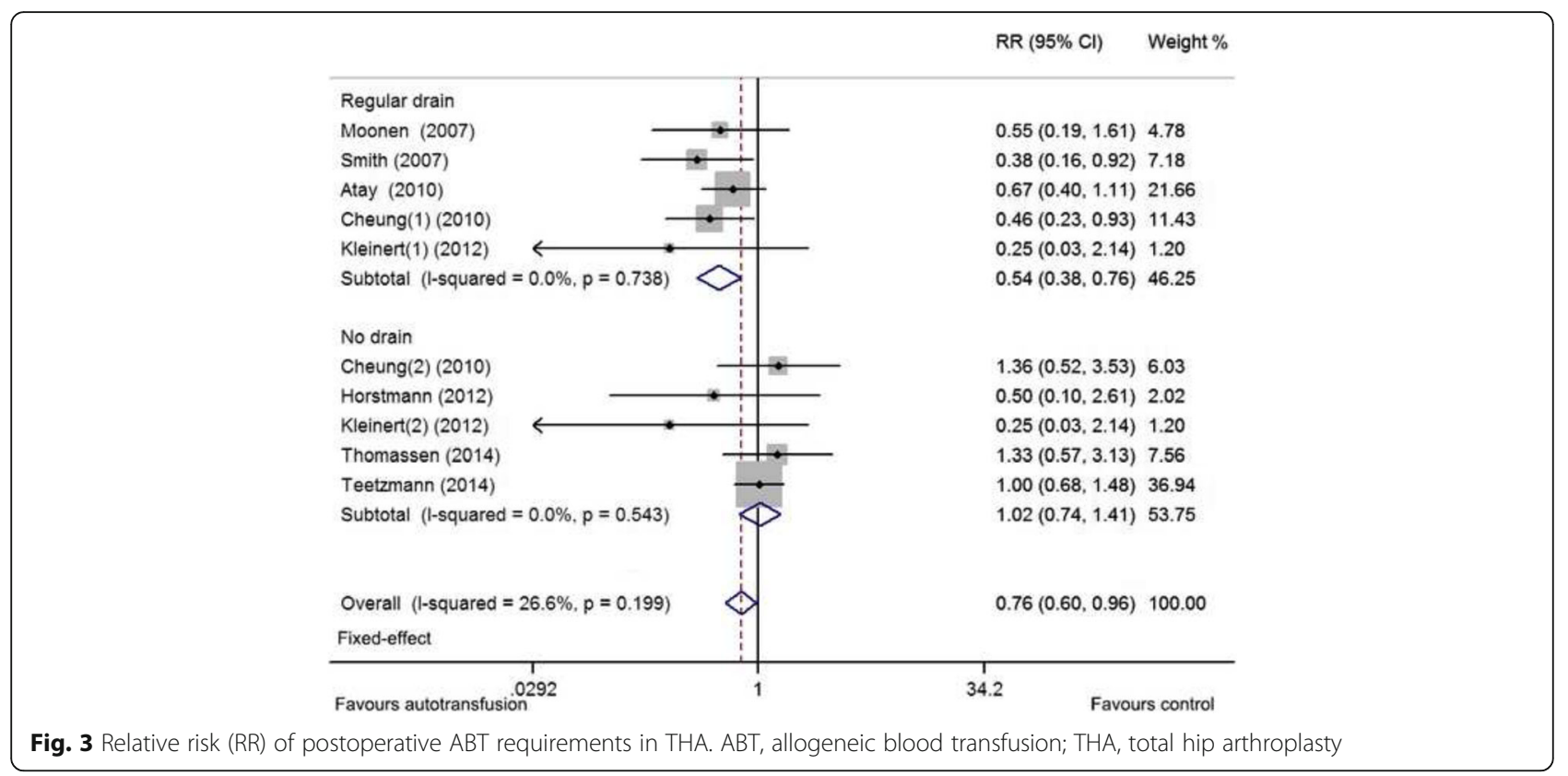

drainage/no drainage group, and no significant difference in adverse reactions was observed between the two groups.

Although our results were positive for autotransfusion, the heterogeneity of the RRs for ABT rate in TKA was a limitation of the meta-analysis. Thus, the reliability of our meta-analytic estimates concerning TKA is questionable due to significant heterogeneity in methodologies. To reduce this heterogeneity in future trials, factors such as the type of system used, Hb triggers, comparison groups, and anesthesia methods should be taken into account. With this in mind, we performed subgroup and sensitivity analyses of the transfusion rates in TKA and THA. We believe that the variability in autotransfusion systems was an important consideration as at least seven autotransfusion systems were used in the 17 RCTs. Moreover, the skill of the operator performing blood reinfusion varied, which could have caused the differences in the volumes of re-infused blood among the studies. Insufficient data from existing RCTs limited our ability to analyze the effects of the different systems.

A previous meta-analysis drew different and incomplete conclusions regarding the benefits of autotransfusion. Zhao et al. and Markar et al. showed that autotransfusion drainage effectively reduced the demand for ABT after total joint arthroplasty when compared with regular drainage $[34,35]$. However, Li et al. found no statistically significant differences in $\mathrm{ABT}$ rate between autotransfusion drainage and no/ regular drainage in THA [36], which could be explained by the fact that only one study was included in the comparison [33].
Our meta-analysis revealed some distinct differences from the findings of previous studies. First, in this study, strict inclusion and exclusion criteria were observed in order to omit studies that implemented anticoagulants in the autotransfusion system $[37,38]$ or were performed without a tourniquet. Anticoagulants and tourniquets would affect blood loss during total joint arthroplasty. Second, two new RCTs were published [22, 23], neither of which showed a significant effect of the autotransfusion system compared with no drainage. In addition, few systematic reviews have considered the differences between autotransfusion drainage and no drainage for both TKA and THA. Finally, our research synthetically analyzed all related studies and gathered comprehensive results regarding the effects of autotransfusion in patients who underwent total joint arthroplasty.

The most important finding of this meta-analysis was that there was no significant difference in $A B T$ rate between autotransfusion drainage and no-drainage. Recently, Thomassen et al. examined 575 patients who underwent primary hip and knee replacement with autotransfusion or no drainage [23]. The authors did not identify any significant difference in the need for ABT between the groups, which is in accordance with our results and those of many other studies (e.g., [13, 18, 22, $24,32,33]$. Although the autotransfusion group had a significant reduction of $\mathrm{ABT}$ rate compared with the regular drainage/no drainage group in our meta-analysis, it is clear that autotransfusion drainage and no drainage have similar effects on ABT reduction.

To date, it remains controversial whether autotransfusion is superior to regular drainage. Atay et al. and 
Moonen et al. reported that the need for ABT was decreased by autotransfusion in both TKA and THA $[2,17]$. Heddle et al. and others reported the same results for TKA alone [12, 14]. In contrast, some studies have shown that the use of an autotransfusion system fails to reduce the need for ABT after TKA $[30,31]$ or THA $[18,33]$. This meta-analysis identified a statistically significant reduction in ABT requirements in patients who underwent autotransfusion drainage when compared with those who received regular drainage following TKA or THA. The previous meta-analyses performed by Markar et al. and Zhao et al. reported the same results for TKA alone [34, 35]. Other meta-analyses also compared regular drainage and no drainage for TKA [39] and THA [40], but there was no support for regular drainage in these reports. In conclusion, autotransfusion drainage and no drainage were superior to regular drainage. The mechanisms underlying these results should be explored in the future.

Adverse reactions including wound infection and febrile reactions were similar in the two groups, which mirrors the findings of previous meta-analyses $[35,36]$. However, significant differences were noted by Zhao et al. between autotransfusion drainage and suction drainage in TKA with regard to febrile reactions [34]. This echoes Soosman's report [41], which suggested a higher rate of febrile reactions than previous reports. Considering the low incidence of febrile reactions and wound infections in our results, we can only infer that autotransfusion drainage had a similar degree of safety when compared with regular drainage/no drainage. Notably, the number of included studies was small, limiting the reliability of these results. Further studies with sufficient data are required to evaluate the safety of autotransfusion systems.

We did not pool the data regarding blood loss volume, amount of blood transfusion per patient, length of hospital stay, and adverse reactions such as DVT and swelling because of insufficient data. Most RCTs stated the protocol for transfusion triggers, but whether strict transfusion rules were followed remains unknown. In addition, the transfusion triggers were not identical among the different RCTs. Thus, a subgroup analysis of transfusion triggers was not appropriate.

This meta-analysis has some limitations. First, the reliability of pooled results concerning TKA is limited by significant heterogeneity in methodological approaches. Second, the number of studies including data related to secondary outcomes was small. Thus, further metaanalyses including more studies and more information on safety outcomes are required in the future. Third, the results were based on many unadjusted factors. A more precise analysis should be conducted that allows for the time of randomization, drain insertion time, timing of drain opening and closing, and financial factors. Finally, the protocol for the systematic review was not prospectively registered. Thus, the transparency of our approach cannot be ascertained.

\section{Conclusion}

Autotransfusion systems reduce the need for ABT compared with regular drainage, but this reduction is not maintained in comparison to procedures that employ no drainage. The use of autotransfusion is characterized by a reduced need for $\mathrm{ABT}$, higher $\mathrm{Hb}$ levels, and similar adverse reactions when compared with control groups (regular drainage and no drainage). However, the reliability of our assessment of secondary outcomes was limited by the inclusion of a small number of studies including these data. Transfusion triggers and the operation procedure should be explored in future study.

\section{Additional files}

\begin{abstract}
Additional file 1: Search strategy. (DOCX $14 \mathrm{~kb}$ )
Additional file 2: Figure S1. Sensitivity analysis of postoperative ABT requirements in TKA. ABT, allogeneic blood transfusion; TKA, total knee arthroplasty. (TIFF $106 \mathrm{~kb}$ )
\end{abstract}

Additional file 3: Figure S2. Weighted mean differences (WMDs) of postoperative hemoglobin ( $\mathrm{Hb}$ ) level in TKA. TKA, total knee arthroplasty. (TIFF 190 kb)

Additional file 4: Figure S3. Relative risk (RR) of postoperative adverse reactions in TKA. TKA, total knee arthroplasty. (TIFF $82 \mathrm{~kb}$ )

Additional file 5: Figure S4. Sensitivity analysis of postoperative ABT requirements in THA. ABT, allogeneic blood transfusion; THA, total hip arthroplasty. (TIFF $84 \mathrm{~kb}$ )

Additional file 6: Figure S5. Weighted mean differences (WMDs) of postoperative hemoglobin (Hb) level in THA. THA, total hip arthroplasty. (TIFF 124 kb)

Additional file 7: Figure S6. Relative risk (RR) of postoperative adverse reactions in THA. THA, total hip arthroplasty. (TIFF $78 \mathrm{~kb}$ )

Additional file 8: Table S1. Publication bias determined using the Egger and Begg's tests. (DOCX 18 kb)

Additional file 9: Figure S7. Funnel plot of included studies for TKA. TKA, total knee arthroplasty. (TIFF $40 \mathrm{~kb}$ )

Additional file 10: Figure S8. Funnel plot of included studies for THA. THA, total hip arthroplasty. (TIFF $39 \mathrm{~kb}$ )

Additional file 11: Dataset. The dataset supporting the conclusions of this article. (XLSX $14 \mathrm{~kb}$ )

Additional file 12: Table S2. The transfusion thresholds and funding source of included studies. (DOCX $87 \mathrm{~kb}$ )

\section{Abbreviations}

ABT: Allogeneic blood transfusion; Cls: Confidence intervals; DVT: Deep vein thrombosis; Hb: Hemoglobin; PRISMA: Preferred Reporting Items for Systematic Reviews and Meta-Analyses; RR: Relative risk; THA: Total hip arthroplasty; TKA: Total knee arthroplasty

Acknowledgements

Not applicable.

Funding

Zhejiang Province education department subject (Y201017108). 


\section{Availability of data and materials}

The datasets supporting the conclusions of this article are included within the article and its additional files (Additional file 11 and Additional file 12: Table S2).

\section{Authors' contributions}

Conceived and designed the analysis: WPJ XFL RXZ. Performed the analysis: WPJ XFL RXZ. Revised the paper/Analysis tools: PT JM XYT QPF BW SWF JFZ SC KMH. Wrote the paper: WPJ XFL RXZ. All authors read and approved the final manuscript.

\section{Ethics approval and consent to participate}

No ethical approval or patient consent was required because all analyses were based on previous published studies.

\section{Consent for publication}

Not applicable.

\section{Competing interests}

The authors declare that they have no competing interests.

\section{Publisher's Note}

Springer Nature remains neutral with regard to jurisdictional claims in published maps and institutional affiliations.

\section{Author details}

'Department of Orthopaedic Surgery, Lishui City People's Hospital, the Sixth Affiliated Hospital of Wenzhou Medical University, Lishui, China. ${ }^{2}$ Department of Orthopaedic Surgery, Sir Run Run Shaw Hospital, Medical College of Zhejiang University, Hangzhou, China.

\section{Received: 4 November 2016 Accepted: 4 August 2017}

\section{Published online: 02 September 2017}

\section{References}

1. Lotke PA, Faralli VJ, Orenstein EM, Ecker ML. Blood loss after total knee replacement. Effects of tourniquet release and continuous passive motion. J Bone Joint Surg Am. 1991;73(7):1037-40.

2. Atay EF, Guven M, Altintas F, Kadioglu B, Ceviz E, Ipek S. Allogeneic blood transfusion decreases with postoperative autotransfusion in hip and knee arthroplasty. Acta Orthop Traumatol Turc. 2010;44(4):306-12.

3. Aksoy $Y$, Altinel L, Kose KC. The comparison of the effects of intraoperative bleeding control and postoperative drain clamping methods on the postoperative blood loss and the need for transfusion following total knee arthroplasty. Acta Orthop Traumatol Turc. 2011;45(3):190-4.

4. Sehat KR, Evans RL, Newman JH. Hidden blood loss following hip and knee arthroplasty. Correct management of blood loss should take hidden loss into account. J Bone Joint Surg Br. 2004;86(4):561-5.

5. Rosencher N, Kerkkamp HE, Macheras G, Munuera LM, Menichella G, Barton DM, Cremers S, Abraham IL. Orthopedic surgery transfusion hemoglobin European overview (OSTHEO) study: blood management in elective knee and hip arthroplasty in Europe. Transfusion. 2003;43(4):459-69.

6. Dodd RY. Current estimates of transfusion safety worldwide. Dev Biol (Basel). 2005;120:3-10.

7. Sarkanovic ML, Gvozdenovic L, Savic D, llic MP, Jovanovic G. Autologous blood transfusion in total knee replacement surgery. Vojnosanit Pregl. 2013;70(3):274-8.

8. Toy PT, Kaplan EB, McVay PA, Lee SJ, Strauss RG, Stehling LC. Blood loss and replacement in total hip arthroplasty: a multicenter study. The preoperative autologous blood donation study group. Transfusion. 1992;32(1):63-7.

9. Woolson ST, Pottorff G. Use of preoperatively deposited autologous blood for total knee replacement. Orthopedics. 1993;16(2):137-41. discussion 141-132

10. Oishi CS, D'Lima DD, Morris BA, Hardwick ME, Berkowitz SD, Colwell CW Jr. Hemodilution with other blood reinfusion techniques in total hip arthroplasty. Clin Orthop Relat Res. 1997;339

11. Sparling EA, Nelson CL, Lavender R, Smith J. The use of erythropoietin in the management of Jehovah's witnesses who have revision total hip arthroplasty. J Bone Joint Surg Am. 1996;78(10):1548-52.

12. Heddle NM, Brox WT, Klama LN, Dickson LL, Levine MN. A randomized trial on the efficacy of an autologous blood drainage and transfusion device in patients undergoing elective knee arthroplasty. Transfusion. 1992;32(8):742-6.

13. Adalberth G, Bystrom S, Kolstad K, Mallmin H, Milbrink J. Postoperative drainage of knee arthroplasty is not necessary: a randomized study of 90 patients. Acta Orthop Scand. 1998;69(5):475-8.

14. Thomas D, Wareham K, Cohen D, Hutchings H. Autologous blood transfusion in total knee replacement surgery. Br J Anaesth. 2001;86(5):669-73.

15. Cheng SC, Hung TS, Tse PY. Investigation of the use of drained blood reinfusion after total knee arthroplasty: a prospective randomised controlled study. J Orthop Surg (Hong Kong). 2005;13(2):120-4.

16. Smith LK, Williams DH, Langkamer VG. Post-operative blood salvage with autologous retransfusion in primary total hip replacement. J Bone Joint Surg Br. 2007;89(8):1092-7.

17. Moonen AF, Knoors NT, van Os JJ, Verburg AD, Pilot P. Retransfusion of filtered shed blood in primary total hip and knee arthroplasty: a prospective randomized clinical trial. Transfusion. 2007;47(3):379-84.

18. Cheung G, Carmont MR, Bing AJ, Kuiper JH, Alcock RJ, Graham NM. No drain, autologous transfusion drain or suction drain? A randomised prospective study in total hip replacement surgery of 168 patients. Acta Orthop Belg. 2010;76(5):619-27.

19. Strumper D, Weber EW, Gielen-Wijffels S, Van Drumpt R, Bulstra S, Slappendel R, Durieux ME, Marcus MA. Clinical efficacy of postoperative autologous transfusion of filtered shed blood in hip and knee arthroplasty. Transfusion. 2004;44(11):1567-71.

20. Ralley FE, Berta D, Binns V, Howard J, Naudie DD. One intraoperative dose of tranexamic acid for patients having primary hip or knee arthroplasty. Clin Orthop Relat Res. 2010;468(7):1905-11.

21. Beer KJ, Lombardi AV Jr, Mallory TH, Vaughn BK. The efficacy of suction drains after routine total joint arthroplasty. J Bone Joint Surg Am. 1991;73(4):584-7.

22. Teetzmann R, Sorensen B, Liseth K, Opheim E, Hervig T. Effects of the Sangvia blood collection system on patients undergoing elective hip surgery. Transfus Apher Sci. 2014;51(2):91-6.

23. Thomassen BJ, den Hollander PH, Kaptijn HH, Nelissen RG, Pilot P. Autologous wound drains have no effect on allogeneic blood transfusions in primary total hip and knee replacement: a three-arm randomised trial. Bone Joint J. 2014;96-B(6):765-71.

24. Horstmann W, Kuipers B, Ohanis D, Slappendel R, Kollen B, Verheyen C. Autologous re-transfusion drain compared with no drain in total knee arthroplasty: a randomised controlled trial. Blood Transfus. 2014;12(Suppl 1):s176-81.

25. Moher D, Liberati A, Tetzlaff J, Altman DG. Preferred reporting items for systematic reviews and meta-analyses: the PRISMA statement. Int I Surg. 2010;8(5):336-41.

26. Smith TO, Hing CB: A meta-analysis of tourniquet assisted arthroscopic knee surgery. Knee 2009, 16(5):317-321.

27. van Tulder M, Furlan A, Bombardier C, Bouter L. Updated method guidelines for systematic reviews in the cochrane collaboration back review group. Spine (Phila Pa 1976). 2003;28(12):1290-9.

28. Higgins JPT GSe: Cochrane Handbook for Systematic Reviews of Interventions Version 5.1.0 [updated March 2011]. The Cochrane Collaboration 2011, Available from http://www.handbook.cochrane.org/.

29. Dramis A, Plewes J. Autologous blood transfusion after primary unilateral total knee replacement surgery. Acta Orthop Belg. 2006;72(1):15-7.

30. Abuzakuk T, Senthil KV, Shenava Y, Bulstrode C, Skinner JA, Cannon SR, Briggs TW. Autotransfusion drains in total knee replacement. Are they alternatives to homologous transfusion? Int Orthop. 2007;31(2):235-9.

31. Amin A, Watson A, Mangwani J, Nawabi DH, Ahluwalia R, Loeffler M. A prospective randomised controlled trial of autologous retransfusion in total knee replacement. J Bone Joint Surg Br. 2008;90(4):451-4.

32. Horstmann WG, Kuipers BM, Slappendel R, Castelein RM, Kollen BJ, Verheyen CC. Postoperative autologous blood transfusion drain or no drain in primary total hip arthroplasty? A randomised controlled trial. Int Orthop. 2012;36(10):2033-9.

33. Kleinert K, Werner C, Mamisch-Saupe N, Kalberer F, Dora C. Closed suction drainage with or without re-transfusion of filtered shed blood does not offer advantages in primary non-cemented total hip replacement using a direct anterior approach. Arch Orthop Trauma Surg. 2012;132(1):131-6.

34. Haien Z, Yong J, Baoan M, Mingjun G, Qingyu F. Post-operative autotransfusion in total hip or knee arthroplasty: a meta-analysis of randomized controlled trials. PLoS One. 2013;8(1):e55073. 
35. Markar SR, Jones GG, Karthikesalingam A, Segaren N, Patel RV. Transfusion drains versus suction drains in total knee replacement: meta-analysis. Knee Surg Sports Traumatol Arthrosc. 2012;20(9):1766-72.

36. Li N, Li P, Liu M, Wang D, Xia L. Comparison between autologous blood transfusion drainage and no drainage/closed-suction drainage in primary total hip arthroplasty: a meta-analysis. Arch Orthop Trauma Surg. 2014;134(11):1623-31.

37. Rs $\mathrm{M}, \mathrm{lc} \mathrm{C}, \mathrm{Jh} \mathrm{N}$. Postoperative collection and reinfusion of autologous blood in total knee arthroplasty. Ann R Coll Surg Engl. 1991;6

38. Newman JH, Bowers M, Murphy J, Newman JH, Bowers M, Murphy J. The clinical advantages of autologous transfusion. Acoustics Speech \& Signal Processing Newsletter IEEE. 1997;79(4):630-2.

39. Quinn M, Bowe A, Galvin R, Dawson P, O'Byrne J. The use of postoperative suction drainage in total knee arthroplasty: a systematic review. Int Orthop. 2015:39(4):653-8.

40. Kelly EG, Cashman JP, Imran FH, Conroy R, O'Byrne J. Systematic review and meta-analysis of closed suction drainage versus non-drainage in primary hip arthroplasty. Surg Technol Int. 2014;24:295-301.

41. So-Osman C, Nelissen RG, Eikenboom HC, Brand A. Efficacy, safety and userfriendliness of two devices for postoperative autologous shed red blood cell re-infusion in elective orthopaedic surgery patients: a randomized pilot study. Transfus Med. 2006;16(5):321-8.

\section{Submit your next manuscript to BioMed Central} and we will help you at every step:

- We accept pre-submission inquiries

- Our selector tool helps you to find the most relevant journal

- We provide round the clock customer support

- Convenient online submission

- Thorough peer review

- Inclusion in PubMed and all major indexing services

- Maximum visibility for your research

Submit your manuscript at www.biomedcentral.com/submit

) Biomed Central 